\title{
MODERN INFORMATION SYSTEMS FOR EFFICIENT MANAGEMENT OF METALLURGICAL PLANTS
}

\author{
Hana ŠPAČKOVÁ, Martin MENŠíK, Jaroslav SLÁČALA, Jan BŘEZINA \\ VSB - Technical University of Ostrava, Ostrava, Czech Republic, EU, \\ hana.spackova.st@vsb.cz
}

https://doi.org/10.37904/metal.2019.779

\begin{abstract}
The paper presents possibilities of a comprehensive (end-to-end) software solution for efficient management of metallurgical plants. The aim of the paper is to point out the high demands of metallurgical enterprises on the information systems, current possibilities of modern ERP and APS systems and trends for more effective and supportive work in these systems. The first chapter focuses on the consolidation of various information systems in metallurgical plants, where unified data structure and business processes can naturally simplify data consolidation into one desired output. Subsequently, the possibilities of modern Enterprise Resource Planning systems and Advanced planning and scheduling systems will be introduced. Modern information systems should undoubtedly record links between partial logistics and production processes. Actual trends will be presented, specifically integrated functionality that complements ERP and APS systems. These advanced functionalities promote the use of standard information systems, primarily to facilitate the data collection through the reporting of employees at the workplace terminals, automatic data collection from machines and the possibility of online access to the latest product documentation. Modern advanced add-on functionalities offer the interconnection of ERP and APS systems with mobile applications, which replace often outdated paper documentation and complex paper-based reporting. Last chapter will introduce requirements and recommendations for the selection of comprehensive information system that meets the high needs of metallurgical plants in the Czech Republic and abroad.
\end{abstract}

Keywords: Metallurgical production, Enterprise Resource Planning, Advanced planning and scheduling, information system

\section{INTRODUCTION}

Nowadays, in many large metallurgical enterprises, a number of paper-based approval acts are underway. Often outdated drawings for production go through the enterprise, data is duplicated into different systems or into excel files for later dedicated use. Let's face it, at the time of advanced digitization and automation, it's not only possible, but is also expected that these outdated methods of sharing information are avoided. Especially in larger enterprises where every information should be unconditionally implemented as part of the system. Medium and higher management without an advanced information system loses a lot of valuable information and reports. The energy of executives is then spent in a totally inefficient way, in the form of demand for supplementary information or to provide background for in-house or external meetings. However, modern information systems have the task of offering their users a number of evaluation reports in their standard. Other reports that the user normally needs can be easily set or programmed. At the same time, the management of information systems also focuses on the use of artificial intelligence methods for more efficient management and operation of the company. Another advantage of a comprehensive information system is the determination of user rights within the system. If we are interested in production, then why not collect data directly from production facilities? Do enterprises know the amount of machine downtimes, their reasons and percentages? The larger the company is the more difficult it is to plan and schedule a large volume of production. At the same time, managing hundreds or thousands of workers is also very demanding. Therefore, the enterprise 
information system, together with automatic or terminal data collection and paperless workshops, can be a solution to focus on important business-enhancing tasks.

The aim of the paper is to point out the high demands of metallurgical enterprises on the information systems, current possibilities of modern ERP and APS systems and trends for more effective and supportive work in these systems.

\section{SYSTEM CONSOLIDATION MEETS THE REQUIREMENTS OF ENTERPRISES}

During the existence of each enterprise, various information systems from different vendors are being deployed to address momentary management issues. However, these various systems (ERP systems, APS, CRM, maintenance or attendance etc.) have usually been integrated by direct linking in the form of data transfer between databases, data file transmission, etc. The complex interconnection of many systems is gradually becoming confusing and unreliable. These established systems very often overlap in terms of functionality (they substitute each other). At the same time, the complicated software structure in the company eliminates future upgrades of individual systems, or the company has to consider excessive costs. An efficient company should thus regularly check these systems to ensure that their operating costs (overhead costs) and human energy are not excessively high. The logical step from this point of view is to approach a system optimization. Thus, the company can become to a phase where it is really worth looking for a comprehensive information system offering integrated solutions for every business area. Such a solution can then guarantee quality and undistorted data suitable for further processing and application of advanced data mining methods. [1]

\section{ERP SYSTEM (ENTERPRISE RESOURCE PLANNING)}

The ERP system usually includes business processes such as logistics and transportation, purchasing and trading activities, warehouse management, accounting, economics and finance, asset management and much more. Metallurgical enterprises inherently require information system that not only encourages repetitive production, but also custom development, warehouse production and many other specific business needs. It can be stated that metallurgical or engineering companies are the most demanding users in terms of the highest demands and needs of production. The ERP system for this kind of business should primarily rationally manage the production process as well as supply and customer logistics chain, meet specific customer requirements, be able to react flexibly to incoming changes, achieve inventory optimization, etc. The primary goal of implementing a quality information system is to achieve automation and create links between business processes.

It's desired to follow link between customer orders, offers, job orders (jobs), finding production needs for specific order, eventually creating a requirement for material purchase, sending a purchase order, receiving material to production, performing manufacturing processes, completing a product, transferring a product to a warehouse and shipping product to the customer. [2] [3]

Retaining and sharing such (normal) enterprise data is a prerequisite for every big business to function. In some systems, the so-called lifecycle is discussed, whereby an authorized user (merchant, etc.) can determine the status of a particular order, what quantity has been delivered, what the available stock is, and where the item is currently located at premises. Customer order document lifecycle form is shown in Figure 1.

\section{APS SYSTEM (ADVANCED PLANNING AND SCHEDULING)}

If APS is not directly part of the ERP system, it is important to implement a specialized Advanced Planning and Scheduling System (APS) after appropriate and properly implemented ERP system. Only the functional and properly implemented ERP system decides on how detailed and correct information will be provided to 
the APS system, which plans and schedules production based on it. In order to maximize use of data from the ERP for planning, it is recommended to look for an ERP system with APS functionality contained in the core of the system. Several systems can be found for this purpose. It is however necessary to verify the actual APS systems function, which are a frequent weakness of comprehensive information systems. High-quality information system vendors can make reference visits to their existing customers to provide potential customers with relevant information on system functionality. [4]

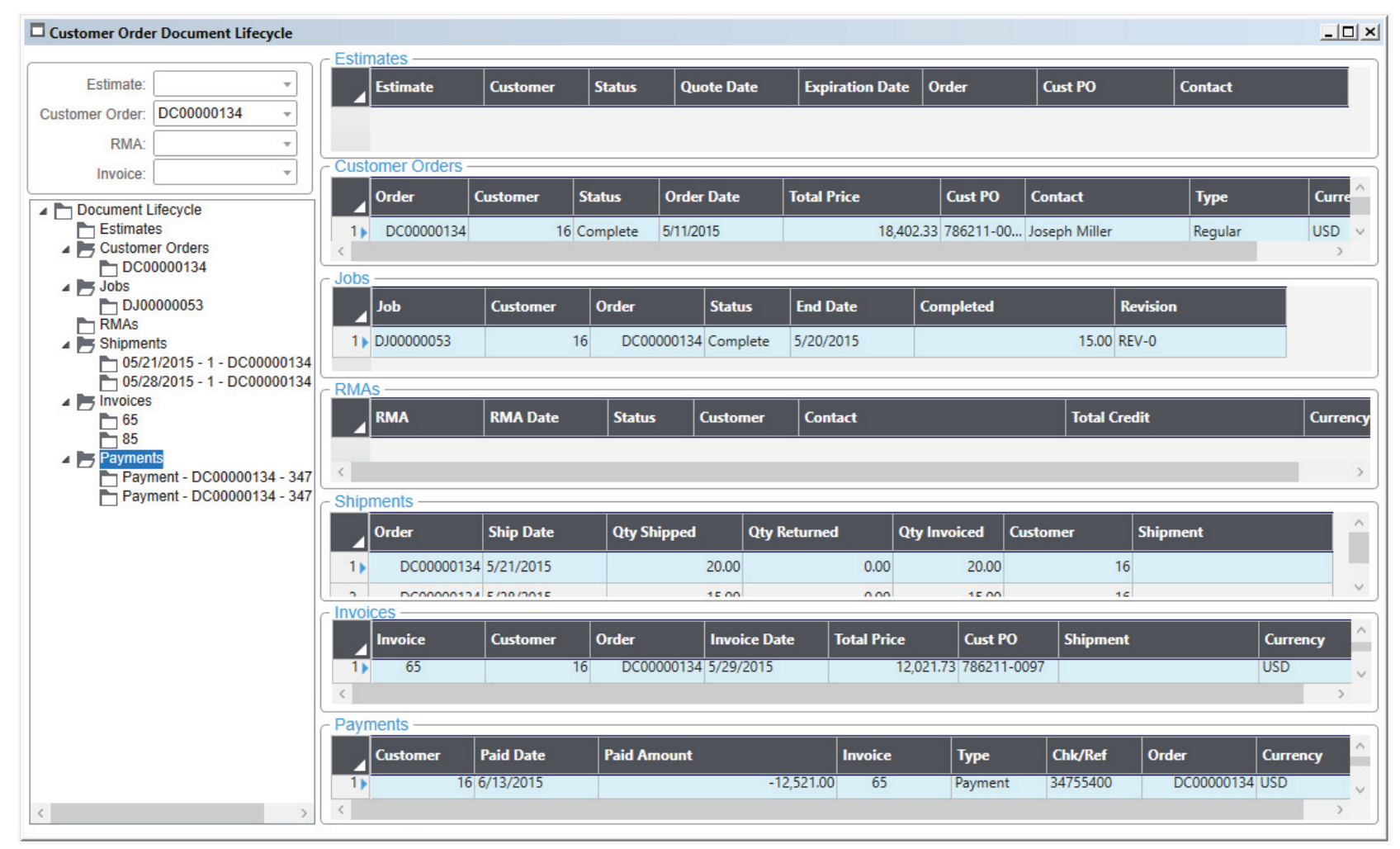

Figure 1 Customer order document lifecycle form [own study]

APS is usually defined as a system with advanced resource planning with limited resources setting. Its goal is to find a balance between production capacities and orders (fulfilment of customer needs). Complex APS system can immediately provide responses about the load and potential impacts of unexpected situations. APS can be seen as a very important tool when making decisions on key issues. Current systems can handle planning alternatives and provide tools to compare them. This part of the system requires some discipline in business processes. It's mainly based on the processes for sorting production operations for individual workplaces or machines, production reporting on individual production operations, in consistent records of cooperation, the feasibility of delivery dates from suppliers, but also in regular maintenance reducing the probability of machine failures, etc. If APS is in mutual compatibility with the ERP system, delivery date can be verified immediately after order acceptance, and planned delivery date can be confirmed to customer as real delivery date (CTP - capable-to-promise). At the same time, it is very important that the system does not only work with one type of resource. It should take into account human capacities when planning and scheduling, the availability of machinery (including planned outages), the availability of tools, molds, manufacturing facilities, etc. Example of Resource Gantt Chart is shown in Figure 2. With the use of a high-quality planning and scheduling system, production capacity can be increased by up to $25 \%$. By identifying the gaps in production capacity utilization, while maintaining existing resources, there is usually a significant increase in business turnover without changing the number of enterprise resources. [5] 
The usual impacts of implementing the APS system are to streamline the workforces, increasing resource utilization, execute orders timely, reduce processing time, reducing inventories in stock, reducing of (un)finished products, accelerating of planning and reschedule when capacity changes, etc.

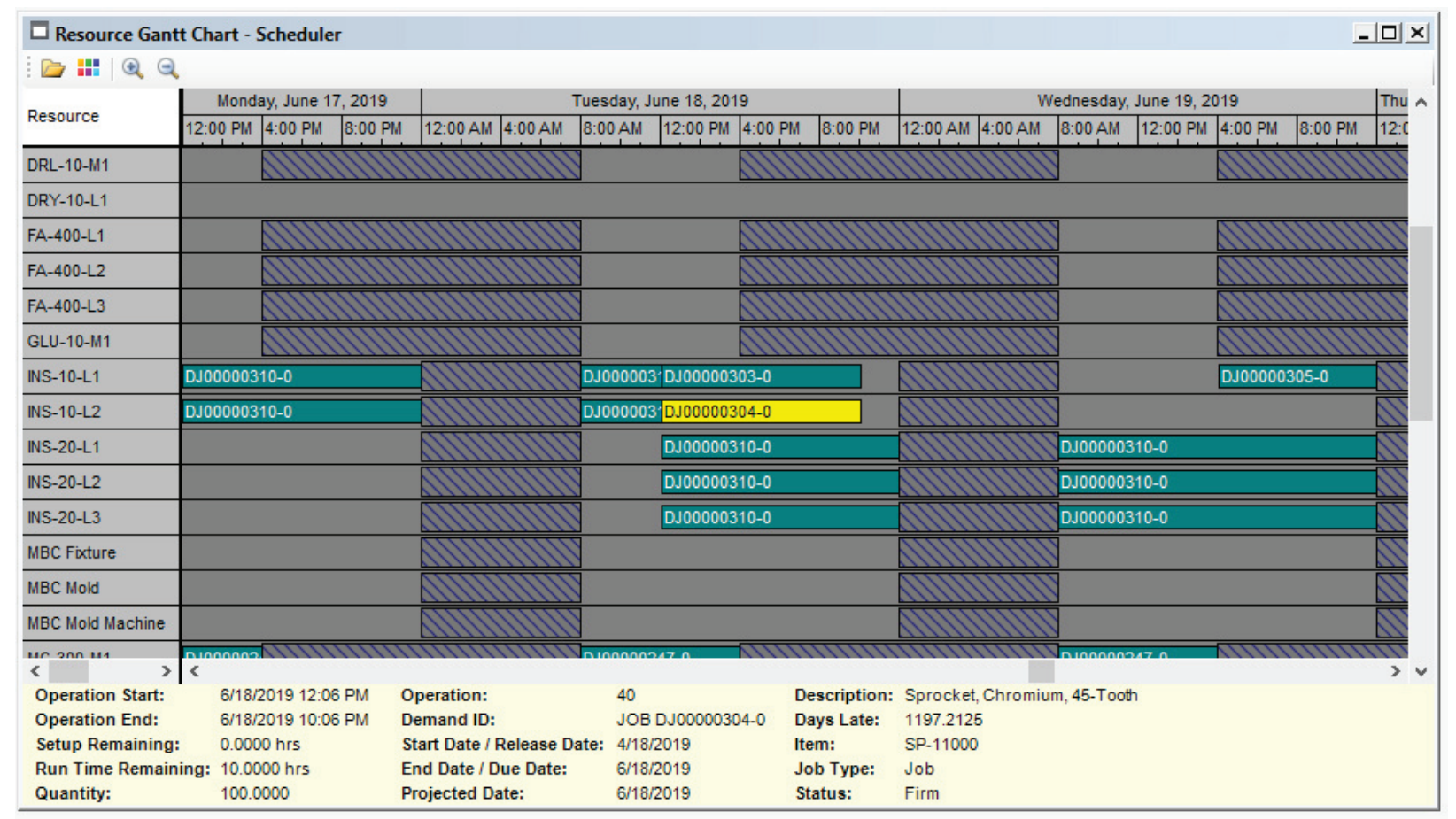

Figure 2 Resource Gantt Chart - Scheduler [own study]

\section{ACTUAL TRENDS IN THE FIELD OF INFORMATION SYSTEMS}

Industry 4.0 and the advancement of digitalization naturally force large (often conservative) businesses to develop further. Opportunities must be seen in the competitive market, but also in the production (operation of metallurgical enterprises). In connection with the use of high-quality ERP and APS systems, there are functionalities that can complete the entire information system solution to the last detail. In metallurgical operations employees can appreciate the benefits of a paperless workshop and the use of a modern job reporting method - terminal data collection. Conversely, technical and economic workers, shift leaders and management of the company will appreciate a high level of data collection from production, subsequent evaluation by data mining methods and searching for weaknesses or reserves of the company for continuous improvement of company processes. Automatic data collection directly from machines to the enterprise information system then provides detailed data on the operation or downtime of individual production facilities. Figure $\mathbf{3}$ shows how the mentioned functionalities work in synergy.

We use smart phones and a variety of mobile applications that can simplify our lives daily. High-quality suppliers of information systems can offer not only a well-designed system solution, but also the possibility of using a mobile application, QR \& Barcode Scanner or a

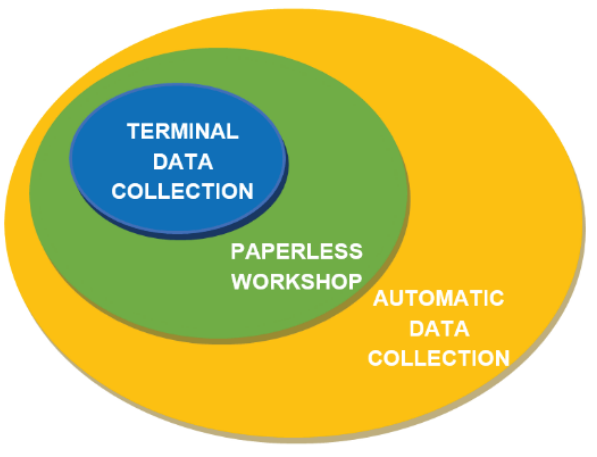

Figure 3 Advanced functionalities complementing the ERP system [own study] web client with full functionality. Thus, workers in demanding and dusty operations, such as metallurgical plants, do not need to keep various forms of paper documentation in production. They can rather work quickly 
and easily with the app on their phone. Whether will workers use fixed terminals, or a mobile app on phone is just a matter of business requirements and investment options.

\section{COMPREHENSIVE INFORMATION SYSTEM COMPLYING WITH METALLURGICAL ENTERPRISES NEEDS}

It is very difficult to find an information system that meets the high demands of manufacturing enterprises even there is variety of diverse systems on the market. The company management should look for a system that comprehensively covers all areas of the business. They should try to avoid creating a new system interface. Priority should be given to choosing a system where functionalities can be used by the company in a standard form (without tailor-made modifications). The reason is simple, every modification of the system becomes more expensive. In addition, it may also be a problem between versions, so when upgrading your system, you may need to rebuild and implement the modification. Approach differs not only for individual systems but also for their suppliers. If it is necessary to introduce special functionality in the company, it is certainly possible to analyze, design, program, test and implement it in the system. [6] It all depends on the requirements and capabilities of the business. At the same time, it is desirable to follow best practices from the same industry.

If the information system works with one of the competitors, there is certainly no reason not to meet the requirements also in other companies within industry. Metallurgical enterprises depend on the quality and efficiency of production, and it is the APS system that should definitely be a key factor in selecting an information solution. At the same time, it is necessary to focus on the process of accepting the order, its planning, production and shipping.

The metallurgical enterprise system should definitely be complemented by the areas of workforce and workplace efficiency management, monitoring utilization of machines, integrated workflow, maintenance and service management and planning, quality management, and more. The aim is to find a system offering "endto-end" solution for whole business process, with opportunity for further company development. If the company really finds such a system, it is necessary to examine and evaluate both the quality and the operational costs for at least 5 years ahead.

The above-mentioned needs and requirements of metallurgical enterprises are definitely fulfilled by the CloudSuite Industrial ERP (SyteLine) enterprise system from Infor, which is supported by Czech InduStream software. Software company Infor, the producer of CloudSuite Industrial, has incorporated more than 5,000 manufacturing enterprises around the world for over 30 years, and is one of the top 3 world producers in enterprise application development. Thus, undoubtedly giving direction to other market players. Above all, it is a proven system for manufacturing companies around the world and at the same time, it offers solutions for a number of large international companies that manage their facilities and plants around the world.

As already mentioned, extensive enterprise system can be significantly streamlined and supported by Czech InduStream software, which takes care of digital data collection and distribution in production or warehouse. At the same time, it is able to provide automatic collection of production data directly from machines. Maintenance and quality workers have therefore up to date data and ability to enter information from any location.

Dozens of large manufacturing companies use Infor CloudSuite Industrial ERP (SyteLine) in the Czech Republic. KOVOLIS HEDVIKOV specializes in casting of aluminum alloys and uses not only Infor CloudSuite Industrial ERP (SyteLine), but also InduStream software from software provider ITeuro. KOVOLIS HEDVIKOV reports that after the introduction of both software solutions, work in progress was reduced by $20 \%$, production time was shortened, job registration was simplified, etc.

The great benefit of Infor CloudSuite Industrial ERP (SyteLine) is the ability to use the system as a multi-site solution that can be used by holdings and international companies operating in multiple countries. The system 
operates in multi-site mode and allows to manage production enterprises e.g in the Czech Republic, the other in Belgium and a sales office in Hong Kong within one software solution.

\section{CONCLUSION}

The key to good relationships with suppliers and customers is the relevance of the information that these parties provide. It is in the interest of every company to promise its customer only a delivery date that is both real and realizable. The company can only reliably achieve this with the right use of available and accurate information, preferably from one comprehensive information system. Information system should be effective management tool not only for company management but all users through the business (end-to-end solution). Extra features to standard ERP can be programmed if necessary, for very specific company requirements.

The information system manufacturer should constantly emphasize further development of software reflecting industry trends. The local software provider should than support manufacturing companies not only with software, but also high expertise in business and manufacturing processes.

The paper summarizes high demands, risks, but especially trends in the area of information systems and other supporting functionalities in connection with the management of metallurgical and other manufacturing companies. Primarily, the current possibilities of ERP and APS systems were described. The article captures the benefits of implementing comprehensive information system into enterprises (with turnover at least 100 millions CZK), including some examples of the information system Infor CloudSuite Industrial ERP (SyteLine) software version 9.01.02.

\section{ACKNOWLEDGEMENTS}

The work was supported by the specific university research of Ministry of Education, Youth and Sports of the Czech Republic No. SP2019/17 and SP2019/62 and company ITeuro, a.s.

\section{REFERENCES}

[1] SEIDL, D., KOŠTIAL, P., JANČíKOVÁ, Z., RUŽIAK, I., RUSNÁKOVÁ, S., FARKAŠOVÁ, M. Modal analysis Measurements versus FEM and artificial neural networks simulation, Communications in Computer and Information Science. 2011. vol. 188. no. 1, pp. 170-175.

[2] POHLUDKA, M., ŠTVERKOVÁ, H., ŚLUSARCZYK, B. Implementation and Unification of the ERP System in a Global Company as a Strategic Decision for Sustainable Entrepreneurship. MDPI. 2018. vol. 10, issue 8, pp. 2916.

[3] CYRUS, K. M., ALOINI, D., KARIMZADEH, S., B. How to Disable Mortal Loops of Enterprise Resource Planning (ERP) Implementation: A System Dynamics Analysis. MDPI. 2018. vol. 6, issue 1, pp. 3-4.

[4] KONVICKA, D., VITALIEVICH, S. V. New generation APS systems for demanding planning environments. In: International May Conference on Strategic Management. Bor: Technical Faculty in Bor, 2018, pp. 60-69.

[5] DAVID, J., VROZINA, M., NOVAKOVA, H. Control of dependability of metallurgical processes such as logistics chains. In: METAL 2012: 21st International Conference on Metallurgy and Materials. Ostrava: TANGER, 2012, pp. 1702-1708.

[6] MONK, Ellen F. and WAGNER, J. Bret. Concepts in Enterprise Resource Planning. 4rd ed. Boston: Course Technology Cengage Learning, 2009. p. 39. 